\title{
Bridging the gap between school and university
}

\author{
How Würzburg University Library \\ supports Information Literacy in \\ Secondary Schools
}

\author{
Viola Hämmer \\ Dr. \\ Würzburg University \\ Germany
}

\begin{abstract}
For almost ten years now the University library of Würzburg is actively involved in the field of information literacy instruction. Along with students, secondary school pupils are the main target group. Last year 1487 pupils attended the courses. The courses are usually held by two librarians and last 90 minutes. They are designed for only up to 25 pupils to guarantee adequate assistance. The main purpose is to enable pupils to find their way through the library autonomous, using pupil-centered, active and collaborative learning methods. The courses begin with the "Cephalonian Method", an active question and answer game, that is followed by the use of pupil-appropriate worksheets. A guided library-tour, containing several self-learning elements, concludes the session.
\end{abstract}

\section{information literacy instruction in secondary schools}

The topic of my talk today is information literacy instruction for pupils at the university library of Würzburg. I'd like to present you our activities in this field - that means what we are doing for pupils, how we are doing it and why we are doing it. At first let me show you the structure of my speech. I've divided my presentation into four major parts:

I'll start off by mentioning some basic parameters. That is, some facts about the city of Würzburg, the schools that are located in and around the town and our reason to engage in the field of information literacy for pupils as an academic library.

In the second part, I'd like to give an overview of our information literacy tutorials. Their concept and the idea of interaction between instructors and pupils during the sessions. I will show you some statistic figures and also talk about evaluation and the aspect of quality.

In the third part I'd like to acquaint you with our additional offers, developed especially for pupils: for instance we reserved a special section on our homepage, tailored for pupils' needs and interests. We also launched a "pupil consultation hour" - actually two hours - once a week.

Finally I'll inform you about the latest developments and the surrounding conditions of our introductory courses. We have to deal with substantial changes in the collaboration between libraries and schools in Bavaria at the moment. Which also means that our course offer has to be adjusted and new concepts have to be developed. 


\section{Basic Parameters}

Let me start with a question: Why should an Academic Library spend time for pupils? Some people might say “Don't you have enough university students that need information skills classes?" Indeed we do have! We have loads of them and we do spend a lot of time on them - we are already very busy to look after our main user group, the academic users.

Let me show you some figures of our active users: on this circular chart you see our active users, divided in groups: nearly 16.000 of them are university students that means $69 \%$. Additionally there are over 700 scientists. In sum $72 \%$ of our active users or nearly 17.000 persons belong to our main user group, they are students or faculty staff. And many of them need assistance in information literacy as well.

Nevertheless pupils play an important role for us. You can see on the chart that $9 \%$ of our users are pupils, which comes up to nearly 2.000 persons, mostly pupils of secondary schools from in and around Würzburg.

In order to give you a good impression of our cooperation with schools, I want to summon a few facts about Würzburg as a city, our library and the schools in Würzburg first. I think this is an important background to understand the conceptional idea behind our tutorials.

\section{City of Würzburg}

The city of Würzburg is a midsize town in northern Bavaria. On the slide you can see, where it is located in Germany. The red dot shows the position of the town. Würzburg has about 130.000 inhabitants and it is renown as an academic town with long tradition in Germany. The first picture on the left shows two of the most famous places in town - the medieval fortress Marienberg and in front the old bridge "Alte Mainbrücke" with its characteristic statues of different Saints.

Würzburg has a lot of schools, among them 11 grammar schools, that means secondary schools that prepare the pupils for university. We mainly cooperate with the grammar schools and the so called "Fachoberschulen" and "Berufsoberschulen" - these are typical German types of schools, which allow young adults with a minor graduation, to improve the degree of education to the standard of A-levels. Usually we don't cooperate with other types of schools, like elementary schools for instance. Our average pupil is between 17 and 19 years old and is preparing for his A-Levels.

The picture in the bottom is the university library of Würzburg which is located on the campus in the outskirts of the town. I'll give more information about our library later on.

\section{The Schools}

On my next slide you find the number of our cooperation partners listed: all 11 grammar schools in Würzburg join our classes regularly, furthermore 48 grammar schools located in the surrounding area of Würzburg, and 19 so called Fachoberschulen and Berufsoberschulen. To give you an impression of how far the pupils and teachers drive to come to us me and my colleagues tried to visualize that on a map: Würzburg is here in the center - marked by the red pin with the "A". All the other red dots symbolize locations of schools that visit our library on a regular basis. Please note the scale in the bottom left corner. The longest journey is undertaken by the pupils of a grammar school in Dinkelsbühl. They drive 110 kilometers one way to get to us. There are a lot of schools that bridge distances of 70 - 80 kilometers to visit our library. 
The main reason why pupils and teachers come to us in the first instance is a thesis all Bavarian pupils have to write in the year before they finish school. The requirements for this thesis have been changed recently by the ministry - and next year will be the first year of pupils writing according to the new rules - I will give you a short outlook on that at the end of my speech. For now, as we don't have any experiences with the new concept yet, I'd like to present the current state.

All Bavarian pupils in grammar schools have to write a first scientific thesis. During their last two years at school all pupils choose two "intensive courses" - two subjects in which they attend many classes. In one of these two subjects they have to write the thesis. The thesis should be completed within 1-years-time and the final paper should have around 20 pages in length. The pupils have to write the thesis on their own that means they have to do it in their spare time in the afternoons. They also have to search for material themselves. The paper has to reach the standards of a scientific paper in citation styles. To give you an impression I have listed some topics we have been confronted with lately:

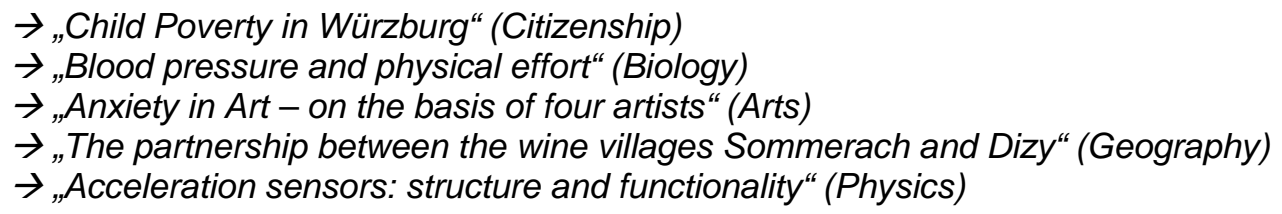

So, as you can see, the topics are often complex and demanding. In most cases the pupils can't find enough information in the public libraries or in their school libraries. Most of the pupils have to consult an academic library in order to find material. Especially in the database and journals sector it's only academic libraries that provide adequate resources for scientific work. And therefore a lot of teachers come with their classes to Würzburg University Library. Further academic libraries in our region are Frankfurt and Nürnberg and both are over $100 \mathrm{~km}$ away.

\section{Würzburg University Library}

What is our offer for pupils? Würzburg University Library consists of one main library and about 70 departmental libraries, institute libraries, and clinical libraries. This quantity of locations is the result of the history of the university. The Library holds about 3.4 million books, substantial media items and over 8.000 current periodicals. We offer information mainly for the subjects that are taught at university and that means - as Würzburg is a full university - we have literature for a wide range of topics. Only the technical subjects like engineering are missing in Würzburg.

Würzburg University Library is financed by the State of Bavaria and as such, it has the designation as a regional library of Franconia. This means we are obligated to collect Franconian imprints (books and other media) and other artefacts that are of historical or cultural significance to the area. And it also means also that we are open to all users not only to academic staff. Pupils can get a library card and use all our services for free. They don't have to pay for it. Mostly pupils use the main library, as it is a lending library in contrast to the other libraries belonging to the Würzburg library system. 


\section{Our information literacy sessions}

Our tutorials started - the way they are now - in 2001. Eight years ago a group of colleagues set up a new concept for introductory classes. Before that we only had traditional library tours. One librarian led a group through the library and informed the people about many aspects of the library. This very teacher-centred, one-directional way of presentation was often sensed as dissatisfying. So in 2001, colleagues tried to find a way to work more interactively. The participants should not only listen, but should get actively involved themselves. We wanted to have practical, hands-on information skills sessions. In our present workshops for pupils we have two basic principles. One is "learning by doing", the other "keep it simple".

The classes last about 90 minutes and are designed for 20 to 25 pupils. Each session is taught by two librarians. Our tutorials are not subject-specific. That means we don't offer classes for biology or mathematics or history or something else. We have the same lesson for all pupils, not regarding the subject they write their thesis in. This is mainly due to practical reasons. In the past we had a lot of classes for different subjects but we had to spend too much time to keep all the material updated.

\section{Goals: The pupils should learn}

What should the pupils learn? We are aiming for different goals in our tutorials:

The most important thing is: we want to assure pupils that they are welcome in our library. A lot of them don't know at all that they may use the university library. They should learn that they are free to ask all questions, to borrow books and use the library like the academic staff. The pupils should lose the fear of the unknown institution after our tutorial.

The second point is that pupils should become autonomous users. We try to teach them how to use the library on their own. Our sessions should be help for self-help.

\section{Finding books in the catalogue and in the library}

Then an important goal is the development of bibliographic search skills. We want to assist the pupils in finding the appropriate information for their research assignments. They should be able to identify adequate resources, and to formulate sensible search strategies. The pupils get to know our online catalogue - which contains the holdings of Würzburg University Library, excluding articles. In the catalogue they learn how to search by title, by author, and by subject. They should understand the organization of the Würzburg library system, and be able to order books - either from Würzburg library itself or from other German libraries via interlibrary loan. We explain the difference between a catalogue and a database, and show how to search for journals in the catalogue and for articles in databases.

As finding books in the catalogue is often as complicated for pupils as finding them in the library we do an extended library tour. Now I want to talk about methodology. Our sessions are characterized by four different methodological parts.

\section{Method 1: Question and Answer Play}

The first one is an interactive question and answer play that lasts about 20 minutes. The librarians welcome the group - which is mostly accompanied by a teacher - in the 
entrance hall. They lead the group in one of our computer-equipped training-rooms, where colored cards with questions on them are placed on every table.

We have four different colors: blue, red, green and yellow. The different colors help us to control the sequence of the questions. Librarians ask first for a blue card. The pupils, who have a blue card, read their question out loud to the group. One example of a blue question is "What does the library offer?" The librarians answer the questions using PowerPoint slides. Other questions are "Where are the books?" or "When I need help, I..." The answer-slides have the same colors as the cards. This method is called the "Cephalonian method" which was described for instance by Morgan \& Davies. After this introduction the pupils have a first impression and are prepared to work on their own in the next part.

\section{Method 2: Pupils Work}

This pupils' work part lasts around 25 minutes. The pupils get a sheet with different tasks. Two examples you can see on my slide: “Find books about „Computer Viruses“ and "Search the database IBZ for articles about ring tones for mobile phones". IBZ is a interdisciplinary database the abbreviation stands for "International bibliography of periodical literature".

The database covers basic research from all fields of knowledge, it is particularly strong in the humanities and the social sciences. The pupils should take their time and solve the tasks on their own. The librarians are around all the time for assistance.

\section{Method 3: Presentation}

After that the librarians sum up the solutions in about 10 minutes. We do that with the help of a PowerPoint presentation with screenshots of catalogue and database. The librarians put emphasis especially on the crucial points, e. g. not searching for article titles in the catalogue. In this presentation part we also give further hints about writing a scientific thesis concerning citation and time management, in plaintext- that it is often helpful not to start too late with their search for material.

As we know from experience that many pupils work on up-to-date topics, such as political incidences, we also give a short overview about newspaper resources, which we do offer in large number in electronic form.

\section{Method 4: Library Tour}

In the end, librarians and pupils go on a tour through the library which takes about 30 minutes. Groups are often divided into two parts in order to have smaller groups in the reading rooms. Every group is attended by one librarian.

In the entrance hall we make stops at the reference desk, the information center that is equipped with more than 100 computers and four printing stations and the circulation desk. Then we proceed to the textbook collection and the reading rooms that are located on the first and on the second floor of the library. There the pupils obtain cards with shelf marks on them. These shelf marks belong to the books and journals they have searched in the catalogue before. Now the pupils have to trace the books and journals in our reading-room and locate a certain article in one of the journals. After that we go back to the computer-room.

Each of the pupils is handed out a sheet with basic library information and an evaluation form.

After the pupils have completed the forms the tutorial is over. Sometimes the pupils stay in the computer-room longer in order to practice a little bit more. 


\section{Organizational facts}

For the success of our workshops some organizational facts are important.

The library has two computer-rooms for instruction. Our first room has 9 computers, the second 18. Both rooms are also equipped with data projectors. So we have very good technical facilities compared to other academic libraries.

15 librarians are teaching the tutorials - most of them reference librarians. All have received special training sessions in didactic and rhetoric fields and are encouraged to improve their skills in further education. In Bavaria there is a group that is occupied with information literacy instruction topics. Two colleagues of us join this group and visit the other academic libraries to learn how instruction is done there.

We are working with a very standardized concept. That means the material is the same for all 15 librarians. We have it on our network drive so all colleagues can have access.

Before I said that the workshops are designed for 20-25 pupils. But sometimes we also have bigger groups. Up to 80 or 90 . Then we use all two instruction rooms, and especially on the library tour we have a very elaborated concept. Here we look that we have small groups that go through the library on different paths. That's important because we don't want that the groups meet each other constantly in the reading rooms.

\section{Evaluation}

We are controlling our activities through a continuing evaluation. After every tutorial the participants get a questionnaire and they are asked to fill it in directly - that means as long as they are in the training room. That way we ensure to obtain feedback of the better part of the participants - we have a rather good sample.

The librarians explain the purpose of the questionnaire and they emphasize that we are really interested in every single opinion and that each of them can help us improving our guided tours. We also have this statement in the first lines on the sheet itself. You can see the heading of it on the screen - I translated it for this talk. We underline this because we want the pupils to take their time to think about the tutorials and fill in the questionnaire carefully.

The questionnaire is one page long - so it doesn't take much time to fill it in. And it consists of open and closed questions. That means questions with ratings or alternative answers and questions where pupils can give the answers on their own. On the next slide I have a section of the questionnaire: We ask for the duration of the tutorial and we ask, if the pupils are pleased with the methods of presentation, the learning by doing and the debriefing afterwards. One question is about the lecturers (which is evaluated, but for personal use).

At the end we have two open questions: "Please look back on the tutorial: What did you like most? What did bother you most?”

Now I will tell you some findings out of this evaluation. First the data basis: 1.556 pupils filled in this questionnaire last school year. That are $96 \%$ of the participants.

To the ratings:

We always ask if the pupils liked our tutorial. This is a very general question. The results last year have been very good. $40 \%$ rated the tutorial absolutely interesting that means gave the 1 on a scale from 1 to 5 . Another $45 \%$ rated the tutorial with 2 on this dimension. Thus we can say that the pupils are rather pleased with our workshops. Only few of them are bored in the classes.

On the next slide I have some findings to our content. We ask the pupils if they think that they are able to search after the tutorial. We are aware that this is only self-assessment and can differ from the abilities in reality but nevertheless it is interesting for us. We ask directly for our three tasks: 
- $\quad$ Searching the catalogue for a specific book

- Searching the catalogue for books on a topic and

- Searching for journal articles

We have also five point scales there and 1 means "absolutely agree”, 5 "absolutely disagree".

$60 \%$ are absolutely sure that they are able to find a book in the catalogue afterwards and another 30\% are also relatively sure. Finding books for a specific topic is not rated as easy as this. You can see it in the second chart on the right. Here $49 \%$ are absolutely sure that the manage the search with keywords and subject headings and $37 \%$ believe it also. The biggest problems pupils face according to our evaluation is searching for journal articles in a database. Only 37\% there are absolutely certain that they will be successful and another $36 \%$ rated 2 on this dimension. But here is also a substantial number of pupils on the 3 which is the middle category. $20 \%$ chose this figure and $7 \%$ think that they are not able to do this. I think this also reflects the complexity of the tasks. Searching for books in the catalogue is rather simple. Searching for articles is more complex and we also don't spend so much time on it. So far to the ratings.

Now some findings of our open questions. We classified the answers to categories to see which points have been mentioned frequently. To the question "What did you like most" we had much more comments than to "What did bother you most?". The pupils liked especially the autonomous work, the examples, and the library tour. Furthermore they were very pleased with the lecturers. They often mentioned their good explanations and the friendly atmosphere.

The negative points mentioned more often were that it's a lot of information in 90 minutes - maybe too much. Some pupils complained that they could not search their own topic but that they have to search our examples. And especially in summer we often can read that the air is bad and stuffy.

As a consequence of our evaluation results we have made many changes on our concept so far. One modification of the last time is the duration of the workshop. Until recently it lasts two full hours. But the pupils often mentioned that it was too long and covered too much information. So we reduced duration to 90 minutes that means now the sessions are half an hour shorter. Since then the results of the evaluation got much better in this point.

\section{Further Services for Pupils}

Although we teach a lot of workshops, many questions remain. In our eyes the need for assistance has been growing over the last years. This may be due to the complexity of the topics and also due to the complexity of the electronic resources. When pupils try to search their own topic they are often confronted with numerous problems nonetheless they attended our classes. Some of them we are able to support adequately at our reference desk - but when it's too complicated we don't have the time that would be necessary to help. So we decided to set up other support ways.

\section{Homepage}

In 2008 we launched a special part on our homepage: The university library for pupils. We inform about registration, about search methods and all our reference and assistance-facilities. We kept the site as simple as possible in order to facilitate the orientation for pupils. The pages also contain suggestions tailored to pupils, for instance "last-minutesearch”, what can you do when sources are missing? And so on. The language is kept simple and a little bit loose in order to make it easy for the pupils. On this part of our homepage we 
give links to various self-study material. Pupils can download information sheets, or start an electronic tutorial of our catalogue.

\section{Pupil consultation hour}

The latest offer we have is a special pupil consultation hour - an offer that is directly addressing pupils who are about to write their thesis. We started with the beginning of school vacations on the sixth of August - that means only some weeks ago. To promote our new offer we have sent emails to our cooperating schools. We also sent them a small poster with the dates for the school notice-board.

The consultation hour is always Thursday in the afternoon and lasts two hours. It's an additional service to our reference desk. We use our computer rooms and give individual assistance to the pupils there concerning their literature research. To our own surprise this offer appeals the pupils very much. In the first week we had 61 pupils, in the second 62 . You have to bear in mind - when interpreting these figures - that pupils had their first vacation weeks and the weather was very sunny and hot. So we think that we will continue with this offer.

\section{Certificate by the ministry - Gütesiegel}

For all our services for pupils in 2009 we got a certificate of the ministry which is called "Gütesiegel“. That means as much as „seal of quality“ and has the additional title „Libraries - Partners of Schools“. This certificate is granted annually to public and academic libraries by the Bavarian State Ministry of Education in cooperation with the State Ministry of Sciences, Research and the Arts. Our university got it for the second time now this year.

Libraries can apply for the certificate. They have to fill in a form and mention all services for pupils. According to the ministry those libraries get the seal that can prove outstanding and close cooperation with schools. The ministry aims at encouraging Bavarian libraries to strengthen their cooperation with schools by initiating this certificate not long ago. Furthermore it should be a symbol of quality and honor of the already existing activities. In 200957 Bavarian Libraries got the Certificate among them only four academic libraries.

This was what we offer at the moment. Due to substantial changes we are already working to provide new services for pupils and schools. Let me talk about this in the last part.

\section{Latest Developments and Work in Progress}

\section{Cooperation Schools - Libraries, “G8”}

What changes do I mean? In Bavaria secondary schools have been reformed some years ago. This process is known under the name 'G8' which stands for eight year grammar school. The pupils spend only eight there not nine like before. This situation was often criticized as "fast-track A-Levels" means covering too much material in too little time. I don't want to speak about the G8 generally now, but about the changes for libraries. The pupils still have to write a scientific thesis. And the scientific work was weighted even stronger than before. Information literacy skills get more and more important. The search for information in G8 is an explicit component of the curriculum. In official documents it's 
stated that schools should cooperate with libraries, with public and academic libraries. Next school year, that means in a few weeks the first pupils will write the thesis in the eight year grammar school. And at the moment there is a relatively high uncertainty under librarians of all library types, because it's not fully clear how the future cooperation should be.

We can say that we appreciate this trend, the emphasizing of cooperation. But we also have to look how we can do more cooperation. For us it's a staffing problem. We are very busy with our academic students so it's really a challenge for us to do more for the pupils.

\section{Subject specific self-learning PowerPoint presentations}

One thing we decided is to offer subject specific assistance especially for pupils. At the moment our subject librarians are scarcely involved in the assistance of pupils. The workshops are done by reference librarians. In order to provide subject relevant search strategies, subject librarians are preparing self-learning tutorials for all school subjects. These tutorials are based on our introductory workshops. They should be the second step for pupils in building information literacy skills. We don't explain the catalogue there or how to do an interlibrary loan. Instead we focus on the specific resources of a subject. For biology this means, i.e.:

- how to find broader and narrower terms to a topic

- which reference works for biology we recommend

- which journals are suitable for pupils

- if it is useful to consult databases or not

- internet-sites or search engines we recommend

Those slides will be ready by the beginning of the new school year in mid September. We will upload them on our homepage - in the part specific for pupils.

\section{Information Literacy for teachers}

Another new development is, that we are thinking about introductory classes for teachers. In the last month we had some requests for such classes. We think that this is also due to the changes in G8 - the teachers now have to tell something about literature research, but maybe their own abilities are not covering up with the latest developments. Information literacy is not a compulsory content in the education of teachers in university. Furthermore there are a lot of changes and for practicing it's important to know the current state. At the moment we don't give classes for teachers but we already have an appointment with the "Teacher training and education centre" located at our university. We have talked about initiating a "further training" for teachers. I think this is a direction we will work in the next time. We are aiming there at making the teachers more confident. We don't want the teachers to replace us as librarians with such introductory classes. Because of constant changes in the resources and the search modes we don't think that this is possible - even if we give workshops to the teachers.

To sum up our offers for pupils, we give introductory classes, and this is the most time-consuming activity. Furthermore we have a special section on our homepage, and a pupil consultation hour once a week. In the near future we will offer also subject-specific self-learning Power Point presentations and information literacy tutorials for teachers. This is all I wanted to say about our services for pupils. In the end I'd like to express that I'm very happy that I had the chance to present you our activities here at this conference and I'd like to thank you very much for your attendance. I put my contact dates here on the last slide if you like to respond to my talk later on - if you have questions now I'd be glad to answer them. 


\section{Statement of Originality}

This statement certifies that the paper above is based upon original research undertaken by the author and that the paper was conceived and written by the author(s) alone and has not been published elsewhere. All information and ideas from others is referenced. 